\title{
The syntactic status of English dative alternation structures in bilingual and in monolingual acquisition data
}

\author{
Raquel Fernández Fuertes and Silvia Sánchez Calderón \\ University of Valladolid Language Acquisition Lab
}

\begin{abstract}
This study deals with the syntactic (non-)derivational relationship of English dative alternation (DA) -double object constructions (DOCs) and to/fordatives-, as seen in the spontaneous production of English-Spanish bilinguals when compared to English monolinguals. While a chronological progression and a difference in use between the two English DA constructions could suggest a syntactic-derivational relationship between DOCs and to/for-datives, a fairly similar emergence and a possibly similar rate of use could point to the two constructions not displaying a syntactic-derivational status. We also explore whether English-Spanish bilinguals show divergent developmental paths when compared to English monolinguals. To address these issues, we analyze data from nine English-Spanish bilingual children and twelve English monolingual children, along with the adults interacting with them. The analysis shows that both DA structures emerge at a similar age, which suggests they are not syntactically derived from one another. Despite these differences, the later onset and the lower incidence of to/for-datives could be associated with the case and theta role mediated properties of prepositions as well as with the frequency of exposure to DA in the adults' speech. As no differences appear between bilinguals and monolinguals, transfer from Spanish does not seem to be an issue.
\end{abstract}

Keywords: English dative alternation, English monolingual corpora, English bilingual corpora, child output, adult input

\section{Introduction}

This study provides an analysis of English dative alternation (DA), as reflected in the spontaneous longitudinal production of English-Spanish bilingual and English monolingual children and the adults that interact with them. An English 
DA verb allows its internal argument structure to alternate between double object constructions (DOCs) (1a-c) and to/for-datives (1b-d) (Larson, 1988; Snyder, 2001; Snyder \& Stromswold, 1997).

(1) a. Give me strawberries

[DOC, Leo, 2;07, the FerFuLice corpus, CHILDES]

b. Give it to daddy

[to-dative, Manuela, 2;01, the Deuchar corpus, CHILDES]

c. I am going to get you a surprise

[DOC, Simon, 5;06, the FerFuLice corpus, CHILDES]

d. I will make a collar for him

[for-dative, Leo, 6;02, the FerFuLice corpus, CHILDES]

Dative alternation can occur in the case of ditransitive structures (1a-b) where the verb 'give' selects the direct object (DO) 'strawberries' and the indirect object (IO) 'me' headed by the preposition 'to'. Or, in the case of mono-transitive structures followed by an adjunct (A) (1c-d), the verb 'get' (1c-d) subcategorizes for the DO 'a surprise' and the A 'you' headed by the preposition 'for' (e.g., Larson, 1988).

We explore how bilingual and monolingual acquisition data can inform regarding the syntactic status of English DA. We aim to examine whether DOCs derive from to/for-datives (Haspelmath, 2006; Larson, 1988; Oehrle, 1976) or to/ for-datives derive from DOCs (Aoun \& Li, 1989; Czepluch, 1982; Dryer, 1986); or whether the two DA constructions are not derivationally related and stem from two different structures (Marantz, 1993; Mulder, 1992) or, rather, share a common underived configuration (Snyder \& Stromswold, 1997). In order to do so, we will analyze acquisition data, comparing across the two child groups (bilingual versus monolingual production) and across the two groups of speakers (child versus adult production).

We further investigate whether the English-Spanish bilinguals' acquisition of English DA follows a similar path to that of English monolinguals. Spanish exhibits some differences from English regarding the properties underlying DA (Cuervo, 2003a, 2003b; Demonte, 1994, 1995; Snyder, 1995, 2001). Rather than showing the presence/absence of the prepositions 'to/for' as in English DA, Spanish is characterized by the presence/absence of a dative clitic 'le' (i.e., him/her, singular) or 'les' (i.e., 'them', plural) in the alternation between dative-clitic-doubled constructions (DCLDs) ((2a) and (2c)) and a/para-datives (2b) and (2d)). Although the

1. We follow Demonte $(1994,1995)$ and Bruhn de Garavito $(2000)$ in the use of the term DCLD to refer to those Spanish structures in which a verb selects a DO as well as a dative clitic which is co-indexed in number, gender and person features, along with Case and theta role properties with a prepositional complement headed by the preposition ' $a$ ' (i.e., 'to'). Other authors (Cuervo, 2003a, 2003b) refer to these structures as double object constructions. However, we 
prepositions ' $a$ ' and 'para' are maintained in Spanish DA, we will make use of the terminology in the field (Bruhn de Garavito, 2000; Demonte, 1994, 1995) and so the term 'DCLD' will be used when an overtly realized pre-verbal dative clitic in the third person (singular or plural) appears, while the term 'a/para-datives' will be used when no overt dative clitic appears (see also footnote 1).

(2) a. (Una bruja) le dice hola a los árboles

(a witch) him-CL.DAT.sG 3sG-say-PRs hello to the trees

'(A witch) says hello to the trees'

[DCLD]

b. (Una bruja) dice hola a los árboles

(a witch) 3sG-say-PRs hello to the trees

'(A witch) says hello to the trees'

[ $a$-dative, Juan, 2;03, the OreaPine corpus, CHILDES]

c. Tú le sabes cocinar papilla a Simon

you him-CL.DAT.SG 2sG-know-PRS cook-INF baby food to Simon

'You know how to cook Simon' baby food

[DCLD]

d. Tú sabes cocinar papilla para Simon

you 2sG-know-PRS cook-INF baby food for Simon

'You know how to cook baby food for Simon'

[para-dative, Leo, 2;08, the FerFuLice corpus, CHILDES]

The structural differences across English and Spanish DA could be reflected in the English-Spanish bilinguals' acquisition of English DA. The syntactic relationship that underlies the two Spanish DA constructions could be transferred into that of the two English DA structures, regardless of whether DOCs and to/for-datives are (non-)derivationally related. If transfer takes place, English-Spanish bilinguals' production would be expected to differ from that of their corresponding English monolingual peers (e.g., Hulk \& Müller, 2001; Rothman, González Alonso \& Puig Mayenco, 2019).

The characterization of English DA will be explored in child output and in adult input so as to determine the role that the frequency of exposure to DOCs and to/for-datives plays in monolinguals' and in bilinguals' production.

The remainder of this paper will be organized as follows. Section 2 presents the formal accounts on the debate regarding the syntactic properties of English and Spanish DA. Section 3 provides a review of previous empirical works.

leave this term for English DA since English DA, unlike Spanish DA, involves the absencepresence of a preposition and does not involve the absence-presence of a dative clitic.

2. Although this instance is a Spanish DCLD, the corresponding English translation equivalent is not a DOC since the verb 'say' does not undergo DA. Therefore, the verbs 'decir' (i.e., 'to say') and 'to say' do not have the same status across the two languages. 
Section 4 presents the study that we have conducted, including our research questions (RQs) (Section 4.1), the selection of English-Spanish bilingual and English monolingual corpora (Section 4.2), and the description of the codification criteria that we have followed with regards to English DA structures (Section 4.3). After the discussion of the statistical tests used for data analysis (Section 4.4) and the data analysis regarding English DA, as reflected in bilingual and in monolingual data (Section 4.5), we present the conclusions and offer suggestions for further research (Section 5).

\section{Syntactic formal accounts on dative alternation structures}

Research on English DA has focused on the syntactic status that relates DOCs and to/for-datives and on investigating whether the two structures undergo a syntactic derivational or non-derivational relationship. This area of study is, still to date, a matter of debate. Such a debate is also present in Spanish, and therefore Spanish DA structures will also be addressed in the present study so that we can determine whether English-Spanish bilinguals transfer the syntactic status that characterizes Spanish DCLDs and a/para-datives when acquiring English DA.

Formal analyses on English DA show no agreement on the syntactic derivational relationship between DOCs and to/for-datives and two approaches have been adopted in this respect. One of these standpoints proposes the derivation of DOCs from to/for-datives via a transformational rule (Oehrle, 1976); or via a passivelike movement that is defined in terms of an advancement rule under Relational Grammar premises (Haspelmath, 2006; Perlmutter, 1990); or a determiner phrase (DP)-movement under Government and Binding theory (Larson, 1988).

Oehrle (1976) assumes that to/for-datives (3) are the base structure. Their internal argument structure follows a canonical order of constituents that is represented in terms of a hierarchical syntactic function-number correspondence based on a scale of prominence. DOCs (4) are argued to be derived from to/for-datives by a transformational rule.

(3) $\mathrm{X}-\mathrm{V}-\mathrm{NP}-$ to/for - NP

$\begin{array}{lcccr}1 & 2 & 3 & \underbrace{4 \quad 5}_{\text {IO }} & \begin{array}{l}\text { [scale of prominence] } \\ \text { [syntactic functions] }\end{array}\end{array}$

[to/for-dative]

(4) $\quad \mathrm{X}-\mathrm{V}-\mathrm{NP}$ - NP

$\begin{array}{lllll}1 & 2 & 5 & 3 & \text { [scale of prominence] }\end{array}$

SU V IO DO [syntactic functions] 
From a Relational Grammar standpoint (Haspelmath, 2006; Perlmutter, 1990), the derivation of DOCs (5b) from to/for-datives (5a) has been argued for in terms of the advancement of the DO over the IO. The DO-2 in the base structure is demoted to an adjunct (or chômeur) position in the derived DA.

(5) a. Pedro $\left[{ }_{V P}\right.$ gave $_{i}\left[{ }_{V P}\right.$ his email address $\left[{ }_{V},\left[{ }_{V} t_{i}\right]\right.$ to Aisha $\left.\left.]\right]\right]$

SU-1 DO-2 IO-3

[to-dative, Haspelmath, 2006, p. 3]

b. Pedro [ ${ }_{V P}$ gave $_{i}\left[{ }_{V P}\right.$ Aisha $_{j}\left[{ }_{V},\left[{ }_{V} t_{i}\right] t_{j}\right.$ his email address $\left.\left.]\right]\right]$ SU-1 DO-2 chômeur

[DOC, Haspelmath, 2006, p. 3]

Larson (1988) proposes that DOCs (6b) derive from to-datives (6a) via DPmovement. The case assigning properties of the preposition 'to' are argued to be absorbed in the formation of the derived DOC, causing the DP 'Mary' (6b) to undergo movement to be assigned accusative case by the verb 'sends'. The DO-DP 'a letter' in the base to-dative assumes an adjunct status in the derived DOC and is assigned inherent accusative case by the reanalyzed complex transitive verb $\left.\left[_{\mathrm{V}} t_{\mathrm{i}}\right] t_{\mathrm{j}}\right]$.

(6) a. John $\left[{ }_{V P} \operatorname{sends}_{\mathrm{i}}\left[_{\mathrm{VP}}\right.\right.$ a letter $\left[\mathrm{V}_{\mathrm{V}}\right.$, to Mary $\left.\left.]\right]\right]$

b. John $\left[{ }_{V P} \operatorname{sends}_{i}\left[{ }_{V P} \operatorname{Mary}_{j}\left[{ }_{V},\left[t_{i}\right] t_{j}\right]\right.\right.$ a letter $\left.\left.]\right]\right]$

[to-dative, Larson, 1988, p. 343]

[DOC, Larson, 1988, p. 353]

By contrast, to/for-datives have also been argued to derive from DOCs. Proponents of the lexical covert-category prepositional phrase (PP) analysis (Czepluch, 1982) argue that to/for-datives (7b) are case-related to DOCs (7a). The null preposition $(e)$ and the verbal trace $\left(t_{\mathrm{i}}\right)$ function as exceptional accusative and inherent accusative case governors in DOCs, thus, complying with the Empty Category Principle (Chomsky, 1981). The case assignment conditions of the derived to-dative are met.

(7) a. John $\left[\mathrm{VP}_{\mathrm{V}}\right.$ gave $_{\mathrm{i}}\left[_{\mathrm{PP}}[\mathrm{P}\right.$ e $]$ Mary $] \mathrm{t}_{\mathrm{i}}[$ the book $\left.]\right]$

[DOC, Czepluch, 1982, p. 14]

b. John gave the book to Mary

[to-dative, Czepluch, 1982, p. 14]

An alternative analysis to the one proposed by Larson (1988) accounts for the derivation of to/for-datives from DOCs via an advancement rule (Dryer, 1986), or via a DP-movement (Aoun \& Li, 1989).

Dryer (1986) argues for DOCs (8a) to be the base structure and for to/fordatives ( $8 \mathrm{~b}$ ) to be the derived structure via the advancement of the DO-DP from a secondary object (SO) position in the base DOC to a primary object (PO) position in the derived to-dative (8b). The IO (PO) in the DOC assumes an adjunct (or a chômeur) status in the to-dative. 
(8) a. John $\left[{ }_{V P}\right.$ gave $_{i}\left[{ }_{V P}\right.$ Mary $\left[{ }_{V},\left[t_{\mathrm{V}}\right]\right.$ the book $\left.\left.]\right]\right]$
SU
$\mathrm{IO}(\mathrm{PO})$
$\mathrm{DO}(\mathrm{SO})$

b. John $\left[{ }_{V P}\right.$ gave $_{i}\left[{ }_{V P}\right.$ the book $\left.{ }_{j},{ }_{V} t_{i}\right] t_{j}$ to Mary $\left.\left.]\right]\right]$

[DOC, Dryer, 1986, p. 821] SU-1 DO-2 chômeur

[to-dative, Dryer, 1986, p. 821]

The derivation of to/for-datives (9b) from DOCs (9a) has also been considered via DP-movement (Aoun \& Li, 1989). Akin to Larson's (1988) proposal, the empty verb in the base DOC lacks the ability to assign case to the DO-DP and causes this constituent to undergo movement to be assigned accusative case by the verb.

(9) a. I $\left[{ }_{\mathrm{VP} 1}\left[\mathrm{~V}\right.\right.$ gave $\left[\mathrm{SC}_{\mathrm{SC}}\right.$ Mary $\left[_{\mathrm{VP} 2}[\mathrm{e}\right.$ a book $\left.\left.\left.\left.]\right]\right]\right]\right]$

b. $\quad\left[_{V P 1}\left[{ }_{V}\right.\right.$ gave $\left[{ }_{S C}\right.$ a book ${ }_{\mathrm{i}}\left[{ }_{V P 2}\left[{ }_{V P 3}\right.\right.$ e t $\left.\mathrm{t}_{\mathrm{i}}\right]$ to Mary $\left.\left.\left.]\right]\right]\right]$

[DOC, Aoun \& Li, 1989, p. 163]

[to-dative, Aoun \& Li, 1989, p. 164]

Non-derivational proposals lend support to the formation of two representations that differ in the head that they project (Marantz, 1993; Mulder, 1992). Marantz (1993) proposes that DOCs and to/for-datives are projected by a null applicative (APPL) affix and by a verb, respectively (10). Mulder (1992) argues that the two English DA structures are headed by an empty causative verb that denotes possession in DOCs or by an empty verbal head in to/for-datives (11).

(10) a. $\left[_{\mathrm{IP}}\left[_{\mathrm{DP}}\right.\right.$ Elmer $]\left[_{\mathrm{I}},\left[_{\mathrm{I}}\right.\right.$ past $]\left[_{\mathrm{VP}}\left[_{\mathrm{DP}}\right.\right.$ Hortense $]\left[_{\mathrm{V}},\left[_{\mathrm{V}}\right.\right.$ give $\left._{\mathrm{i}}+\mathrm{APPL}\right]\left[_{\mathrm{VP}}\left[_{\mathrm{DP}}\right.\right.$ the porcupine $\left.\left.\left.\left.\left.]\left[{ }_{V},\left[t_{\mathrm{i}}\right]\right]\right]\right]\right]\right]\right]$

[DOC, adapted from Marantz, 1993, p. 119]

b. $\left[_{\mathrm{IP}}\left[_{\mathrm{DP}}\right.\right.$ Elmer $]\left[_{\mathrm{I}},\left[_{\mathrm{I}}\right.\right.$ past $]\left[_{\mathrm{VP}}\left[_{\mathrm{DP}}\right.\right.$ the porcupine $]\left[_{\mathrm{V}},\left[_{\mathrm{V}}\right.\right.$ give $]\left[_{\mathrm{PP}}\right.$ to Hortense]]]]]

[to-dative, adapted from Marantz, 1993, p. 120]

(11) a. I [ ${ }_{\mathrm{VP}}$ gave $\left[_{\mathrm{SC}}\right.$ John $\phi_{\mathrm{HAVE}}$ the book] $]$

b. I $\left[{ }_{\mathrm{VP}}\right.$ gave $\left[{ }_{\mathrm{SC}}\right.$ the book $\phi$ to John $\left.]\right]$

[DOC, Mulder, 1992, p. 69]

[to-dative, Mulder, 1992, p. 69]

Snyder and Stromswold (1997) suggest that DOCs and to/for-datives constitute a natural syntactic class of complex predicate constructions (Larson, 1988; Marantz, 1993) or SC structures (Aoun \& Li, 1989). In the light of this proposal, English DA is argued to depend on a shared parametric property in which the verb (1) forms a syntactic complex predicate with a secondary predicate and both constituents are semantically similar to a simple verb; or (2) selects an SC that includes the internal structure of DOCs and to/for-datives. This is captured in the Complex Predicate Parameter (Snyder, 1995, 2001), which determines that there 
is a parametric distinction between the availability of DA structures in English, a [+complex predicate] language, and Spanish, a [-complex predicate] language. More specifically, the Complex Predicate Parameter (Snyder, 1995, 2001) argues that direct counterparts of English DOCs are not available in Spanish, and so, Spanish DCLDs do not share a similar status to that of English DOCs.

Within the domain of Spanish DA, there seems to be an agreement in earlier works on the syntactic derivation of DCLDs (12b) from a/para-datives (12a) via the spell-out or the non-overt realization of a dative clitic 'le' ('him/her') or 'les' ('them') (Bruhn de Garavito, 2000; Demonte, 1994, 1995). Nevertheless, Demonte (1994, 1995) does not account for the pre-verbal position of the dative clitic, and therefore, further research is required in this regard.

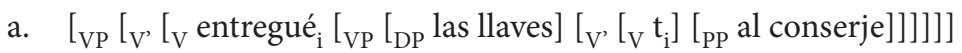 [a-dative, adapted from Demonte, 1995, p. 16]

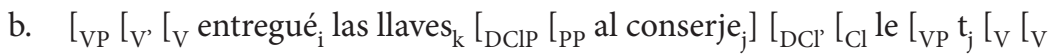 $\left.\left.\left.\left.\left.\left.\left.\left.\mathrm{t}_{\mathrm{i}}\right]\left[\mathrm{DP}_{\mathrm{k}} \mathrm{t}\right]\right]\right]\right]\right]\right]\right]\right]$

[DCLDs, adapted from Demonte, 1995, p. 17-18]

From a non-derivational approach, Cuervo (2003a, 2003b) suggests that DCLDs (13a) and $a$-datives (13b) correspond to two structures that differ in the syntactic status of the head they project, namely, a dative clitic that functions as an applicative head (Pylkkänen, 2002) in DCLDs (13b) and a verb in $a$-datives (13a).
a. Andrea envió
un diccionario a Gabi
Andrea 3sG-send-PST a dictionary to Gabi
'Andrea sent a dictionary to Gabi'
[TP [] [T] [[Andrea] [[v] [[V envió] [[Theme un diccionario] [P a] [Goal Gabi]]]]]]]]

b. Andrea le envió un diccionario a Gabi

Andrea him-CL.DAT.sg 3sg-send-PST a dictionary to Gabi

'Andrea sent Gabi a dictionary'

[TP [Andrea] [[T le enviók] [[ $\left.\mathrm{t}_{\mathrm{j}}\right]$ [vP [un diccionarioi] [ $\left[\mathrm{v}_{\mathrm{j}}+\mathrm{t}_{\mathrm{k}}\right]\left[\left[\mathrm{V} \mathrm{v} \mathrm{t}_{\mathrm{j}}\right.\right.$ $\left.+t_{k}\right]\left[\left[\right.\right.$ Beneficiary a Gabi] [[Appl le $\left.e_{j}\right]$ [Theme ti]]]]]]]]]

The debate on the syntactic relationship between the two English and Spanish DA structures is still ongoing. In order to contribute to the debate on the syntactic derivational status (or lack thereof) that relates the two English DA structures, we examine English-Spanish bilingual and English monolingual children's acquisition data. As discussed in Section 4.1, a subsequent order in the onset and in the incidence of to/for-datives when compared to DOCs, as reflected in the EnglishSpanish bilingual and in the English monolingual children's data, could suggest that the former are more grammatically complex structures (i.e., the one being 
derived) whereas the latter are the basic less complex DA constructions (i.e., the original underived structure). Alternatively, non-significant differences in the two variables under analysis (namely, emergence and production patterns) could infer that similar grammatical requirements are needed to produce the two DA structures, suggesting a non-derivational relation between DOCs and to/for-datives. A third implication of this study is that the syntactic status that relates the two Spanish DA constructions could be playing a role in the bilinguals' acquisition of the syntactic relationship between DOCs and to/for-datives. If this is the case, differences when comparing English-Spanish bilinguals' acquisition of English DA structures to that of English monolinguals should appear. That is, English-Spanish bilinguals could reflect a delay in the acquisition of English DA as a result of the transfer from the syntactic properties that connect the two Spanish DA constructions. If these results point in this direction, further research is needed to examine the English-Spanish bilinguals' acquisition of DA in their other language (i.e., Spanish), when compared to Spanish monolinguals' data.

\section{Dative alternation in acquisition studies}

Two main issues have centered the discussion on the production of English and Spanish DA by children: the age of onset and the influence of adult input in child output.

With regards to English DA, empirical works have reported the earlier onset of DOCs if compared to to/for-datives both in bilinguals (Gu, 2010) and in monolinguals (Campbell \& Tomasello, 2001; Gropen, Pinker, Hollander, Goldberg, \& Wilson, 1989; Snyder \& Stromswold, 1997). The longitudinal spontaneous data used in these studies are taken from the CHIld Language Data Exchange System (CHILDES; MacWhinney, 2000). A summary of the mean ages of onset of DOCs and to/for-datives in each of these earlier empirical works is provided in Table 1.

Table 1. Mean age of onset of English dative alternation in bilingual and in monolingual empirical works

\begin{tabular}{lcc}
\hline Empirical works & DOCs & to/for-datives \\
\hline Gu (2010)-bilinguals & $2 ; 00$ & $2 ; 09$ \\
Campbell and Tomasello (2001)-monolinguals & $2 ; 02$ & $2 ; 04$ \\
Gropen et al. (1989)-monolinguals & $2 ; 06$ & $2 ; 07$ \\
Snyder and Stromswold (1997)-monolinguals & $2 ; 02$ & $2 ; 06$ \\
\hline
\end{tabular}

Note. Adapted from Campbell and Tomasello (2001); Gropen et al. (1989); Gu (2010), and Snyder and Stromswold (1997). 
Although English DA structures show an order of emergence in acquisition data (Table 1), Snyder and Stromswold (1997) observe that DOCs and to-datives appear at a similar age $(r=.76, p=.0043) .^{3}$ This is argued to be due to English DA structures all being acquired as part of the syntactic package of complex predicates that share a parametric property (or Property A), as captured in the Complex Predicate Parameter (Snyder, 1995, 2001). However, according to Snyder and Stromswold's (1997) study, the later onset of to-datives if compared to DOCs $(t(1)=4.15$, $p=.002$ ) is subject to an additional property (or Property B) that is associated with the dative case and with the recipient theta role mediated assigning properties of the preposition 'to' via the verb onto the DP (Larson, 1988; Marantz, 1984). That the preposition holds such special status is evidenced in the English monolingual children's data in the correlation $(r=.83, p=.0009)$ between the ages of onset of to-datives and other related dative structures (namely, dyadic to-datives) which show a concurrent mean age of onset at 2;06.

To date, very few bilingual and monolingual works have accounted for the acquisition of Spanish DA. Indeed, only Torrens and Wexler (2000) have reported on the onset of DCLDs, while no works have been concerned with either the acquisition of a/para-datives or that of the two types of Spanish DA constructions.

The study conducted by Torrens and Wexler (2000) analyzes the spontaneous production data of a Spanish monolingual child and, in particular, they establish a comparison between DA constructions (14a) and structures which do not allow dative clitic optionality with pronominal prepositional complements, and in which, therefore, dative alternation is not allowed (14b). Their findings reveal that these two types of structures start being produced at an early age, namely, between 1;07 and 2;03.
a. (Le) $)_{\mathrm{i}}$ voy
a dar
$\operatorname{arroz}[\text { a mi niño }]_{i}$
him.cl.dat. go.1p.sg. pres. to give.inf. rice to my baby
'I'm going to give rice to my baby'
b. $\mathrm{Te}_{\mathrm{i}}$ voy a hacer una foto $[\mathrm{a} \mathrm{ti}]_{\mathrm{i}}$
you.cl.dat. go.1p.sg. pres. to take.inf. a picture to you
'I'm going to take a picture of you'

[María, 2;04, the Ornat corpus, CHILDES, Torrens \& Wexler, 2000, p. 288]

Since our study is not concerned with structures which do not allow dative alternation, we have not analyzed these types of data and have not, therefore, made any

3. Snyder and Stromswold's (1997) codification criteria of English DA is analogous to those followed in the present study (see Section 4.3). Some of the English monolingual corpora that they selected has also been included in this study (namely, the Brown corpus, the MacWhinney corpus, the Sachs corpus and the Suppes corpus; see Section 4.2). 
predictions in this respect. The present paper focuses on the analysis of Spanish DA in which the dative clitic is in the third person, that is, is obligatory, since, following Demonte $(1994,1995)$, this is the case where the alternation between the presence or the absence of the dative clitic holds in the formation of DCLDs and a/para-datives, respectively.

Based on these findings, Torrens and Wexler (2000) conclude that the child begins to produce DA constructions and structures that do not allow dative clitic optionality in Spanish at an early stage. These data show a native-like knowledge of the use of the dative clitic, in accordance with the Full Competence Hypothesis (Poeppel \& Wexler, 1993). These authors, however, do not discuss the other Spanish DA structure, a/para-datives.

Previous studies on English monolinguals have yielded opposing results with respect to the role that adult input plays in child output. On the one hand, the relative frequency of exposure to a construction in the adult input is argued to play a role in the child output (Legate \& Yang, 2002; Yang, 2016). For example, Campbell and Tomasello (2001) observe that the adults' preference for DOCs (mean: 65.7\%) over to-datives (mean: $34.3 \%$ ) correlates with the English monolingual children's higher rates in the use of DOCs (mean: 68\%) and with the lower rates in the use of to-datives (mean: $32 \%)(p<.01)$.

Other works such as the one conducted by Snyder and Stromswold (1997) report that the relative frequency of exposure to DOCs (mean: $73.2 \%$ ) and to-datives (mean: 26.8\%) in the adult input with the verb 'give' does not correlate $(p>.10)$ with the earlier emergence of DOCs (mean age: 2;02) if compared to to-datives (mean age: 2;06) in the English monolingual children's output.

The comparison on the emergence of English DA between English-Spanish bilinguals and English monolinguals has not received a lot of attention as of yet and neither has the role of adult input in the case of English-Spanish bilingual and Spanish monolingual acquisition (Sánchez Calderón \& Fernández Fuertes, 2016, 2018). All these studies observe that the earlier onset of DOCs when compared to to/for-datives, as analyzed in a set of English-Spanish bilingual twins' data, is influenced by the relative frequency of use in the adult input.

To the best of our knowledge, no previous works have been conducted on the role played by adult input in bilingual and in monolingual children's production of Spanish DA. 


\section{English dative alternation in bilingual and in monolingual acquisition data}

\subsection{Research questions}

Taking previous theoretical accounts (Section 2) and empirical works (Section 3) as a point of departure, four RQs have been formulated. These RQs aim at providing an answer for the debate concerning the syntactic derivational relationship (or lack thereof) between the two English DA structures in English-Spanish bilinguals' and in English monolinguals' data (RQ 1) as well as the role played by adult input in child output (RQ 2).

- RQ 1. What is the syntactic relationship between DOCs and to/for-datives, as reflected in the English monolinguals' ages of onset?

In this respect, the English monolinguals' data could go in two different directions: (1) DOCs or to/for-datives may show a significantly later emergence when compared to the DA counterpart, suggesting that one of the two DA constructions is syntactically derived from the other (e.g., Dryer, 1986; Haspelmath, 2006; Larson, 1988); or (2) DOCs and to/for-datives may emerge at a similar age, which would suggest that the two English DA structures are non-derivationally related in syntax (e.g., Marantz, 1993; Mulder, 1992; Snyder \& Stromswold, 1997).

We expect the two English DA constructions not to syntactically derive from one another, as observed in the English monolinguals' non-significant differences in the emergence of the two constructions (Snyder \& Stromswold, 1997). Despite the rather similar age of onset, we also expect a delay in the English monolinguals' onset of to/for-datives when compared to DOCs (Campbell \& Tomasello, 2001; Gropen et al., 1989; Snyder \& Stromswold, 1997), given the additional grammatical properties of the prepositions (Larson, 1988; Marantz, 1984; Snyder \& Stromswold, 1997).

- RQ 2. Is the acquisition of the syntactic relationship between DOCs and to/ for-datives by English-Spanish bilinguals similar to that of their respective English monolingual peers?

RQ 2 aims to investigate whether the English-Spanish bilinguals' acquisition of the syntactic relationship between DOCs and to/for-datives proceeds like in their monolingual peers, as per the Autonomous Development Hypothesis (ADH; Clark, 2009; Genesee, Nicoladis \& Paradis, 1995; Paradis \& Genesee, 1996); or rather, whether English-Spanish bilinguals transfer the syntactic DA status into their other first language (i.e., Spanish), making English-Spanish bilinguals differ from English monolinguals in this respect, as per the Interdependence Development Hypothesis (IDH; Meisel, 2004; Paradis \& Genesee, 1996). 
As per the Complex Predicate Parameter (Snyder, 1995, 2001), the syntactic properties that underlie DA differ across English and Spanish (see Section 1). Despite this contrast and given the monolingual-like patterns in the bilinguals' production of English DA, we expect English-Spanish bilinguals to acquire both the syntactic non-derivational relationship between DOCs and to/for-datives and the additional grammatical properties of the latter, akin to their English monolingual peers (see RQ 1) (e.g., Gu, 2010). If these predictions are correct, results would comply with the ADH, and therefore, the syntactic status that characterizes DCLDs and a/para-datives in the English-Spanish bilinguals' other language would not be a source of transfer in the bilinguals' acquisition of English DA.

- RQ 3. Does the frequency of exposure to DOCs and to/for-datives in the adult input play a role in the English monolinguals' output?

Taking as a starting point earlier works on the role played by adult input in English monolingual children's output (e.g., Campbell \& Tomasello, 2001; Snyder \& Stromswold, 1997), ${ }^{4}$ we expect adults to show higher frequency rates in the use of DOCs when compared to to/for-datives (e.g., in line with works that argue for the relevance of language exposure in boosting child language acquisition; Legate \& Yang, 2002; Yang, 2016).

- RQ 4. Does the frequency of exposure to DOCs and to/for-datives in the adult input play a role in the English-Spanish bilinguals' output, when compared to their monolingual peers?

Considering the results reported by previous works on the role that adult input plays in child output (e.g., Legate \& Yang, 2002; Yang, 2016), we expect both English-Spanish bilinguals' and English monolinguals' production to correlate to that of the adults that constitute their primary input.

In order to provide an answer to the four RQs formulated above, the following sections will discuss the methodology that has been implemented in this study as well as the analysis of English DA in English-Spanish bilinguals' and in English monolinguals' data.

4. As will be discussed in Section 4.3, the present study examines the production of DOCs and to/for-datives in every DA verb produced by the adults and by the English monolingual children selected. It also reports the overall (and collapsed) relative frequency rates of all the verbs produced by the two target groups (adults and children). We, therefore, offer a more comprehensive view of DA in acquisition data in that in Campbell and Tomasello's (2001) analysis DOCs and to/for-datives are considered from a lexico-semantic approach, and in Snyder and Stromswold's (1997) only DOCs and to-datives with the verb 'give' are discussed in the adult input and in the children's output. 


\subsection{Participants and corpora selection}

A total of eleven corpora have been selected from the CHILDES (MacWhinney, 2000), an open access database (http://childes.psy.cmu.edu). As shown in Table 2, the data selection includes the spontaneous longitudinal production of nine English-Spanish bilinguals (three girls and six boys) and twelve English monolinguals (seven girls and five boys).

Table 2. Selected English-Spanish bilingual and English monolingual corpora

\begin{tabular}{|c|c|c|c|c|c|}
\hline Corpora & & \# files examined & Child & Gender & $\overline{\text { Age range }}$ \\
\hline \multirow[t]{8}{*}{$\begin{array}{l}\text { Bilingual } \\
\text { English- } \\
\text { Spanish }\end{array}$} & Deuchar & $\begin{array}{c}11 \\
\text { [010308.cha] to } \\
\text { [020621.cha] }\end{array}$ & Manuela & $\mathrm{F}$ & $1 ; 03-3 ; 03$ \\
\hline & FerFuLice & $\begin{array}{c}115 \\
\text { [010122.cha] to } \\
\text { [061019.cha] }\end{array}$ & Leo and Simon & M & $1 ; 01-6 ; 11$ \\
\hline & Pérez & $\begin{array}{c}16 \\
\text { [010227.cha] to } \\
\text { [030006.cha] }\end{array}$ & Alberto & M & $1 ; 08-3 ; 00$ \\
\hline & & $\begin{array}{c}3 \\
\text { [021117.cha] to } \\
\text { [030122.cha] }\end{array}$ & Antonio & M & $2 ; 11-3 ; 02$ \\
\hline & & $\begin{array}{c}21 \\
\text { [011129.cha] to } \\
\text { [030321.cha] }\end{array}$ & Carla & $\mathrm{F}$ & $2 ; 00-3 ; 03$ \\
\hline & & $\begin{array}{c}6 \\
\text { [020118.cha] to } \\
\text { [030503.cha] }\end{array}$ & John & M & $2 ; 00-3 ; 03$ \\
\hline & & $\begin{array}{c}2 \\
\text { [020212.cha] to } \\
\text { [021101.cha] }\end{array}$ & Sheila & $\mathrm{F}$ & $2 ; 02-2 ; 11$ \\
\hline & Ticio & $\begin{array}{c}13 \\
\text { [010616.cha] to } \\
\text { [011017.cha] }\end{array}$ & Diego & M & $1 ; 06-2 ; 04$ \\
\hline \multirow[t]{2}{*}{$\begin{array}{l}\text { Monolingual } \\
\text { English }\end{array}$} & Brown & $\begin{array}{c}55 \\
\text { [020304.cha] to } \\
\text { [050212.cha] }\end{array}$ & Adam & M & $2 ; 03-4 ; 10$ \\
\hline & & $\begin{array}{c}20 \\
\text { [010600.cha] to } \\
\text { [020300b.cha] }\end{array}$ & Eve & $\mathrm{F}$ & $1 ; 06-2 ; 03$ \\
\hline
\end{tabular}


Table 2. (continued)

\begin{tabular}{|c|c|c|c|c|c|}
\hline Corpora & & \# files examined & Child & Gender & Age range \\
\hline & & $\begin{array}{c}129 \\
{[020305 . c h a] \text { to }} \\
{[050106 . c h a]}\end{array}$ & Sarah & $\mathrm{F}$ & $2 ; 03-5 ; 01$ \\
\hline & \multirow[t]{2}{*}{ Cruttenden } & $\begin{array}{c}21 \\
\text { [010517.cha] to } \\
\text { [030718.cha] }\end{array}$ & Jane and Lucy & $\mathrm{F}$ & $1 ; 05-3 ; 07$ \\
\hline & & $\begin{array}{c}21 \\
\text { [010517.cha] to } \\
\text { [030618b.cha] }\end{array}$ & & & \\
\hline & Lara & $\begin{array}{c}20 \\
\text { [010913.cha] to } \\
\text { [030325.cha] }\end{array}$ & Lara & $\mathrm{F}$ & $1 ; 09-3 ; 03$ \\
\hline & \multirow[t]{2}{*}{ MacWhinney } & $\begin{array}{c}292 \\
\text { [010411a.cha] to } \\
\text { [070802.cha] }\end{array}$ & Mark & M & $0 ; 07-5 ; 06$ \\
\hline & & $\begin{array}{c}292 \\
\text { [010411a.cha] to } \\
\text { [070802.cha] }\end{array}$ & Ross & $\mathrm{F}$ & $0 ; 06-8 ; 00$ \\
\hline & Sachs & $\begin{array}{c}83 \\
\text { [010229.cha] to } \\
\text { [040903.cha] }\end{array}$ & Naomi & $\mathrm{F}$ & $1 ; 01-5 ; 01$ \\
\hline & Suppes & $\begin{array}{c}52 \\
\text { [011116.cha] to } \\
\text { [030321.cha] }\end{array}$ & Nina & $\mathrm{F}$ & $1 ; 11-3 ; 11$ \\
\hline & \multirow[t]{3}{*}{ Wells } & $\begin{array}{c}10 \\
{[010521 . c h a] \text { to }} \\
{[050024 . c h a]}\end{array}$ & Benjamin & M & $2 ; 03-5 ; 00$ \\
\hline & & $\begin{array}{c}9 \\
\text { [010606.cha] to } \\
\text { [040905.cha] }\end{array}$ & Gerald & $\mathrm{M}$ & $1 ; 06-4 ; 09$ \\
\hline & & $\begin{array}{c}10 \\
\text { [010526.cha] to } \\
\text { [040901.cha] }\end{array}$ & Jack & M & $1 ; 05-4 ; 09$ \\
\hline
\end{tabular}

Data have been originally audio-recorded and then transcribed in the CHAT (Codes for the Human Analysis of Transcripts) format for the CHILDES project. Our analysis is conducted on the transcripts. This selection is based on the data available in CHILDES and, although the amount of data available varies between children, the number of participants is balanced when comparing across the two language groups. The children have a homogeneous profile in that (1) the 
bilinguals are all simultaneous bilinguals, that is, children that have been exposed to the two languages from birth and in a natural context; (2) the monolinguals have been exposed to one language from birth; (3) the children's longitudinal production occurs in spontaneous naturalistic setting; and (4) none of the children show speech or hearing disabilities. The selection comprises the age range from $1 ; 11$ to 6;11 in English-Spanish bilinguals and from 0;06 to 8;00 in English monolinguals. Regarding the eleven corpora, a complete record of the transcriptions of the children's spontaneous speech in the home context and in the interactions (usually) with their parents is freely available on-line through the CHILDES database.

Adult input has also been considered in the two target language groups. Parents are the main source of input as well as other caregivers (grandparents, uncles, aunts) and researchers that also contribute to the children's language exposure. The implementation of the rule of Grammont (i.e., the one-parent one-language strategy; Ronjat, 1913) provides a fairly similar amount of exposure to the two languages in the case of bilingual children. (e.g., Paradis, Crago, \& Genesee, 2006). Therefore, the English-Spanish bilingual children's language proficiency in English and in Spanish is fairly balanced and they show similar developmental patterns to their corresponding monolingual peers (e.g., De Houwer, 1990, 2005; Meisel, 2004), as per the ADH. Therefore, the selection of English DA constructions will consider those scenarios in which parents, caregivers and researchers address the selected English-Spanish bilingual children in English.

\subsection{Codification criteria}

DA structures have been extracted both manually and automatically via the KWAL command (Key Word And Line) designed to work with data from CHILDES. KWAL has been used to carry out an automatic morpho-syntactic search for the contexts in which the keyword verb (with the code ' $\mathrm{v}^{*}$ ') is produced by children and by adults. This search is conducted in those selected corpora that display a $+\mathrm{t}$ \%mor (morphological tier) in their CHAT transcripts (mainly, English monolingual corpora, with the exception of the Lara corpus). The specific syntax line used in this case is the following: kwal $+\mathrm{t}^{\star} \mathrm{CHI}+\mathrm{t} \% \mathrm{mor}+\mathrm{s}^{\text {“c }} \mathrm{v}^{\star ”}-\mathrm{w} 2+\mathrm{w} 2 .{ }^{5}$ Manual

5. The command string indicates (a) the name of the target command (KWAL); (b) the participants that are targeted, in this case the child $\left(+\mathrm{t}^{\star} \mathrm{CHI}\right)$; (c) the morphology dependent tier where the search is actually conducted ( $+\mathrm{t} \%$ mor) since this is where the participant's utterances are morphologically tagged; (d) the strings to be searched, in this case the verb and, in order to include the different verbal form, namely, continuous and past tenses or the $-\mathrm{s}$ in third person of present tense, an asterisk is used ( ${ }^{\star} \mathrm{s}^{\text {“ }} \mathrm{v}^{\star}$ ); (e) the additional context that is to be output, in this case two utterances preceding and two following the utterance in which the keyword " $\mathrm{v}$ " appears (-w2 and +w2, respectively); and (f) the files under analysis in the corpora selected (@). 
extraction of DA structures has been carried out in those selected corpora that do not have $\mathrm{a}+\mathrm{t} \%$ mor line, that is, the Lara corpus (English monolingual corpus) and all the selected English-Spanish bilingual corpora.

Given that KWAL does not distinguish utterances in terms of their verbal subcategorization (e.g., DA constructions, intransitives, mono-transitives, among others) or the constituent order of their arguments, the KWAL output has been manually trimmed to only display the target constructions for analysis. ${ }^{6}$ Four criteria have been followed in the selection of English DA structures with a subjectverb-object constituent order, namely, utterances in which a verb subcategorizes for (1) a DO-DP and an IO-PP headed by the preposition 'to'; (2) a DO-DP as well as an A-PP headed by the preposition 'for'; (3) an IO-DP and a DO-DP; as well as (4) an A-DP and a DO-DP. These criteria have also been followed for the manual extraction of the target constructions both in the child and in the adult data.

Once English DA constructions have been extracted, they have been codified in terms of DOCs (15) and to/for-datives (16), both for English-Spanish bilinguals' and for English monolinguals' data.

(15) a. Show me what the directions are

[DOC, Adam, 4;10, the MacWhinney corpus, CHILDES]

b. You buy me a motorbike

[DOC, Jane, 3;06, the Cruttenden corpus, CHILDES]

(16) a. You give that one to me

[to-dative, Jane, 2;09, the Cruttenden corpus, CHILDES]

b. I buy cereal for my baby

[for-dative, Ross, 2;08, the MacWhinney corpus, CHILDES]

Declarative (affirmative and negative) and imperative English DA utterances have been considered for classification. Wh-interrogative English DA structures (17) have been excluded from the data analysis since wh-movement might distort the order differences in the DA mechanism. We have also discarded (1) fronted DO-DPs in declarative English DA structures with a discourse emphatic purpose (18a); (2) null verbs, null arguments and null adjuncts in constructions that would otherwise undergo DA (18b); (3) locative mono-transitive structures (18c); and (c) for-datives with an exchange, reason or time meaning (18d-f). The reason for

6. An example of the KWAL output is provided below for Ross' production of a DOC:

${ }^{\star} \mathrm{CHI}$ : grandpa gave me these toys.

\%mor: grand\#n|pa v|give\&PAST pro:obj|me pro:dem|these n|toy-PL.

[File 27b1.cha, line 889, Ross, the MacWhinney corpus, CHILDES] 
exclusion is that these patterns might interfere with the word-order issues under consideration in this study.

(17) What ${ }_{\mathrm{i}}$ are you giving me $t_{\mathrm{i}}$ ?

[wh-interrogative DOC, Jack, 3;03, the Wells corpus, CHILDES]

(18) a. The one I showed you

[DOC, fronted DO-DP, Ross, 3;02, the MacWhinney corpus, CHILDES]

b. He gives $(\mathrm{e})_{\mathrm{DO}}$ to me

[to-dative; null DO, Simon, 3;10, the FerFuLice corpus, CHILDES]

c. Shall I drive you to the doctors?

[locative mono-transitive, Lara, 3;00, the Lara corpus, CHILDES]

d. Change it for a dime

[exchange for-dative, Adam, 4;09, the Brown corpus, CHILDES]

e. Don't spank me for this

[reason adverb clause, Ross, 5;03, the MacWhinney corpus, CHILDES]

f. I got the one for Christmas

[time adverb clause, Ross, 6;07, the MacWhinney corpus, CHILDES]

Longitudinally, the production of English DA has been divided into thirteen age groups with intervals of six and five months ranging from age 1;00-1;06 (age group 1) to age 7;00-7;06 (age group 13), as displayed in Table 3. We have taken as a point of departure the five linguistic stages in child language development (e.g., Bel \& Rosado, 2009; Rowland, 2014) and they have been established on the basis of the participants' age range in the two target language groups (i.e., English monolinguals and English-Spanish bilinguals), namely, from 0;06 to 8;00.

Table 3. Age groups for the study of English dative alternation

\begin{tabular}{cccc}
\hline Age group & Age range & Age group & Age range \\
\hline 1 & $1 ; 00-1 ; 06$ & 8 & $4 ; 07-4 ; 11$ \\
2 & $1 ; 07-1 ; 11$ & 9 & $5 ; 00-5 ; 06$ \\
3 & $2 ; 00-2 ; 06$ & 10 & $5 ; 07-5 ; 11$ \\
4 & $2 ; 07-2 ; 11$ & 11 & $6 ; 00-6 ; 06$ \\
5 & $3 ; 00-3 ; 06$ & 12 & $6 ; 07-6 ; 11$ \\
6 & $3 ; 07-3 ; 11$ & 13 & $7 ; 00-7 ; 06$ \\
7 & $4 ; 00-4 ; 06$ & & \\
\hline
\end{tabular}

Ages preceding age group 1 and following age group 13 are not considered for the data analysis. A preliminary analysis of the data has revealed that English DA is not produced in either of the two target language groups prior to age $1 ; 00$. In addition, as we are concerned with the emergence of DA and given that by age 5;00 all 
children have acquired the basic properties of the grammar of the language(s) they are exposed to (Peccei, 1999), we set age 7;06 as the final age of the study period.

\subsection{Statistical tests used for data analyses}

The SPSS was used to run two types of statistical tests to explore whether the emergence of English DA can explain the acquisition of the syntactic derivational relationship (or lack thereof) between DOCs and to/for-datives. We also examine whether differences are seen between English-Spanish bilinguals' data and English monolinguals' data in the onset of English DA.

More specifically, the parametric two-tailed paired-sample $t$-test has been run when data are normally distributed, and homogeneity of variance is assumed. This test has been used in the analysis of the emergence of English DA in the data from each target language group, namely, English monolinguals and English-Spanish bilinguals.

Alternatively, the non-parametric Mann-Whitney $U$ test has been implemented to compare the ages of onset of each target construction (i.e., DOCs, on the one hand, and to/for-datives, on the other hand) across the two target language groups. This non-parametric test has been run when data are asymmetrically distributed and skewed.

\subsection{Data analysis}

English DA structures show an order of emergence, that is, DOCs start being produced earlier than to/for-datives and this is observed both in EnglishSpanish bilinguals' data and in English monolinguals' data, as illustrated in the last row in Table 4.

Such a chronological progression has also been reported in previous works on bilingual English (Gu, 2010; Sánchez Calderón \& Fernández Fuertes, 2016, 2018) as well as in previous works on monolingual English (Campbell \& Tomasello, 2001; Gropen et al., 1989; Snyder \& Stromswold, 1997). As shown in Table 5, when the statistical analyses are reported, these point to a significant difference between the earlier emergence of DOCs compared to to/for-datives.

Regarding the age range of onset, English-Spanish bilinguals start producing DOCs between 2;01 and 2;05 and to/for-datives are observed to emerge between 2;01 and 3;02. In the case of English monolinguals' data, the onset of English DA structures ranges from 1;04 to 2;09 in DOCs and from 1;11 to 3;02 in to/for-datives.

As shown in Table 4 and as reflected in the order in which the participants appear in the Table, three of the nine English-Spanish bilinguals display an earlier onset of DOCs when compared to to/for-datives and one English-Spanish bilingual 
Table 4. Age of onset of English dative alternation in English-Spanish bilinguals and in English monolinguals

\begin{tabular}{|c|c|c|c|c|c|}
\hline \multicolumn{3}{|c|}{ English-Spanish bilinguals } & \multicolumn{3}{|c|}{ English monolinguals } \\
\hline Children & DOCs & to/for-datives & Children & DOCs & to/for-datives \\
\hline Simon & $2 ; 03$ & $3 ; 02$ & Ross & $1 ; 04$ & $2 ; 06$ \\
\hline Leo & $2 ; 05$ & $3 ; 01$ & Eve & $1 ; 08$ & $1 ; 11$ \\
\hline John & $2 ; 04$ & $2 ; 11$ & Jane & $1 ; 11$ & $2 ; 06$ \\
\hline Manuela & $2 ; 01$ & $2 ; 01$ & Nina & $2 ; 01$ & $2 ; 11$ \\
\hline Alberto & - & $2 ; 02$ & Adam & $2 ; 04$ & $2 ; 11$ \\
\hline Antonio & - & $2 ; 11$ & Mark & $2 ; 06$ & $2 ; 09$ \\
\hline Sheila & - & - & Sarah & $2 ; 09$ & $3 ; 02$ \\
\hline Carla & - & - & Naomi & $2 ; 01$ & $2 ; 00$ \\
\hline \multirow[t]{5}{*}{ Diego } & - & - & Lara & $2 ; 06$ & $2 ; 04$ \\
\hline & & & Lucy & $2 ; 07$ & $2 ; 00$ \\
\hline & & & Benjamin & $2 ; 03$ & - \\
\hline & & & Jack & $2 ; 02$ & - \\
\hline & & & Gerald & - & $2 ; 11$ \\
\hline Mean & $2 ; 03$ & $2 ; 08$ & Mean & $2 ; 02$ & $2 ; 06$ \\
\hline
\end{tabular}

child starts producing English DA structures concurrently at 2;01. Furthermore, two of the nine English-Spanish bilinguals only produce to/for-datives and three of them do not produce the target constructions at all. With regards to English monolinguals' data, seven of the thirteen English monolinguals show an earlier onset of DOCs when compared to to/for-datives and three English monolinguals only produce one of the two English DA constructions.

Despite the order of onset, the parametric two-tailed paired-sample $t$-test statistical analysis shows that the two English DA constructions seem to emerge at a similar age both in bilinguals $(t(4)=-1.858, p=.160)$ and in monolinguals $(t(11)=-2.079, p=.067)$. Differences are not seen when the emergence of each structure is compared across the two target language groups, namely, DOCs $(U=14.000, p=.562)$, on the one hand, and to/for-datives $(U=23.000, p=.308)$, on the other hand, as reported by the non-parametric Mann-Whitney $U$ test. These findings suggest that DOCs and to/for-datives are not derivationally related given that derivation would trigger a delay in the acquisition process of one of the two English DA structures (i.e., the derived structure) and this is not the case in English-Spanish bilinguals' or in English monolinguals' data. This means that our results lend support to the formal analysis of a shared underlying complex predicate or SC structure (Snyder \& Stromswold, 1997), as per the Complex Predicate 
Table 5. Statistical results and rationale of previous empirical works on the emergence of English dative alternation in English-Spanish bilinguals and in English monolinguals

\begin{tabular}{|c|c|c|c|c|}
\hline $\begin{array}{l}\text { Target } \\
\text { children }\end{array}$ & Empirical work & $\begin{array}{l}\text { Mean age of } \\
\text { emergence }\end{array}$ & $\begin{array}{l}\text { Statistical } \\
\text { results }\end{array}$ & Rationale \\
\hline \multirow[t]{2}{*}{$\begin{array}{l}\text { English- } \\
\text { Spanish } \\
\text { bilinguals }\end{array}$} & $\mathrm{Gu}(2010)$ & $\begin{array}{l}\text { DOCs } \\
(2 ; 00)>\text { to/for- } \\
\text { datives }(2 ; 09)\end{array}$ & Unreported & Adult input effects \\
\hline & $\begin{array}{l}\text { Sánchez } \\
\text { Calderón and } \\
\text { Fernández } \\
\text { Fuertes (2016, } \\
\text { 2018) }\end{array}$ & $\begin{array}{l}\text { DOCs } \\
(2 ; 03)>\text { to/for- } \\
\text { datives }(3 ; 01)\end{array}$ & Unreported & $\begin{array}{l}\text { Syntactic derivation of } t o / \\
\text { for-datives from DOCs } \\
\text { Semantic motion require- } \\
\text { ments (cause-Go) in the } \\
\text { later emergence of to/ } \\
\text { for-datives } \\
\text { Adult input conditions }\end{array}$ \\
\hline \multirow[t]{3}{*}{$\begin{array}{l}\text { English } \\
\text { monolin- } \\
\text { guals }\end{array}$} & $\begin{array}{l}\text { Campbell and } \\
\text { Tomasello (2001) }\end{array}$ & $\begin{array}{l}\text { DOCs } \\
(2 ; 02)>\text { to/for- } \\
\text { datives }(2 ; 04)\end{array}$ & $p<.01$ & $\begin{array}{l}\text { Significant correlation } \\
\text { between onset of the two } \\
\text { English DA constructions } \\
\text { and frequency of exposure } \\
\text { in adult input }\end{array}$ \\
\hline & $\begin{array}{l}\text { Gropen et al. } \\
(1989)\end{array}$ & $\begin{array}{l}\text { DOCs } \\
(2 ; 06)>\text { to/for- } \\
\text { datives }(2 ; 07)\end{array}$ & Unreported & $\begin{array}{l}\text { Children have used DA } \\
\text { verbs with a giving seman- } \\
\text { tic approach, regardless of } \\
\text { the type of DA structure }\end{array}$ \\
\hline & $\begin{array}{l}\text { Snyder and } \\
\text { Stromswold } \\
(1997)\end{array}$ & $\begin{array}{l}\text { DOCs } \\
(2 ; 02)>\text { to/for- } \\
\text { datives }(2 ; 06)\end{array}$ & $\begin{array}{l}r=.76 \\
p=.0043 \text { and } \\
t(11)=4.15 \\
p=.002\end{array}$ & $\begin{array}{l}\text { Significant correlation: } \\
\text { shared underlying structure } \\
\text { (Property A) } \\
\text { Significant differences: } \\
\text { additional properties of to/ } \\
\text { for-datives (Property B) }\end{array}$ \\
\hline
\end{tabular}

Parameter (Snyder, 1995, 2001). Even if not statistically significant, the later emergence of to/for-datives when compared to DOCs in English-Spanish bilinguals' and in English monolinguals' data alike suggests that these structures require additional properties in their production. These properties, as suggested in previous formal accounts, involve the dative case and the recipient/beneficiary theta role mediated assignment of the prepositions 'to/for' to the DP via the verb (Larson, 1988; Marantz, 1984; Snyder \& Stromswold, 1997).

An overview of the English DA production is provided in Table 6 for EnglishSpanish bilingual and for English monolingual children. Considering the overall incidence of English DA structures (100\%), DOCs turn out to be more frequently used than to/for-datives in both of the two target language groups. 
Table 6. Overall production of English dative alternation in English-Spanish bilinguals and in English monolinguals (\# of raw numbers (\%))

\begin{tabular}{lccr}
\hline Language group & DOCs & To/for-datives & \multicolumn{1}{c}{ Total } \\
\hline English-Spanish bilinguals & $136(80.5 \%)$ & $33(19.5 \%)$ & $169(100 \%)$ \\
English monolinguals & $752(74.2 \%)$ & $262(25.8 \%)$ & $1,014(100 \%)$ \\
\hline
\end{tabular}

This order regarding the use of English DA structures is also reflected developmentally both in English-Spanish bilingual children's data $(t(8)=-4.335, p=.002)$ and in English monolingual children's data $(t(11)=-4.453, p=.001)$.

With regards to the English monolinguals' overall production of DA, the incidence of DOCs reflects a gradual increase from the age group of onset at 1;00-1;06 (5 occurrences, $0.5 \%$ ) to 3;00-3;06 (172 occurrences, 17.0\%), age group from which the use of DOCs begins to decrease until 7;00-7;06 (18 occurrences, $1.8 \%$ ), as depicted in Figure 1 . The incidence of to/for-datives appears to be consistently low from the onset at $1 ; 07-1 ; 11$ (2 occurrences, $0.2 \%$ ) to $7 ; 00-7 ; 06$ (4 occurrences, $0.4 \%$ ).

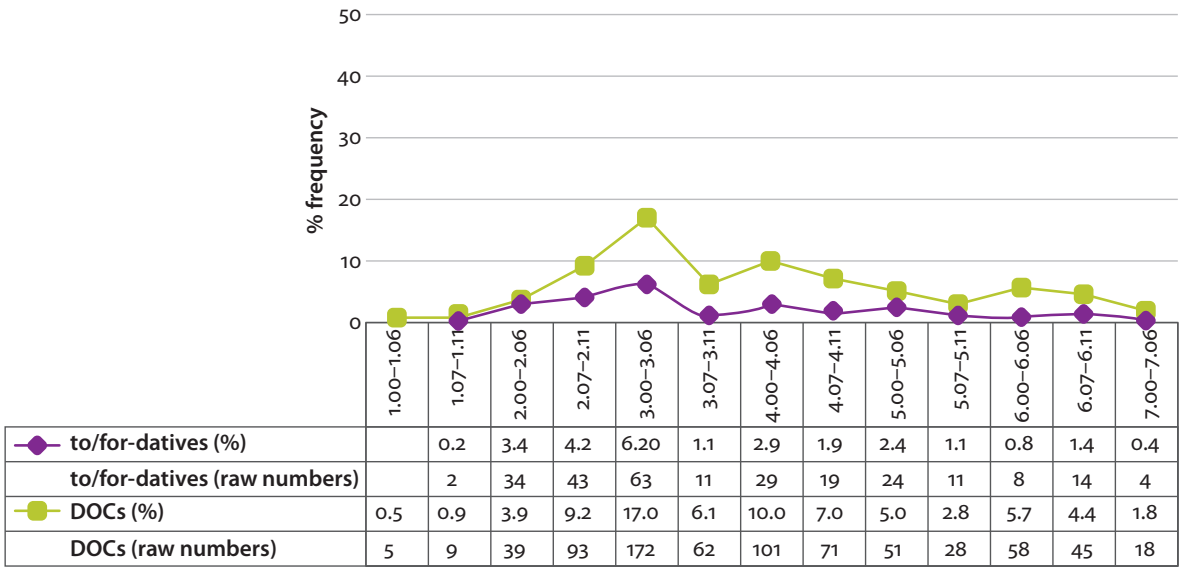

Figure 1. English monolinguals' production of English dative alternation per age groups [100\% $=$ overall DA structures produced by English monolinguals]

As illustrated in Figure 2, English-Spanish bilinguals gradually increase the production of DOCs from the age group of onset at 2;00-2;06 (1 occurrence, $0.6 \%$ ) to 4;00-4;06 (24 occurrences, $14.2 \%$ ), age group from which DOCs gradually decrease in use until 6;07-6;11 (13 occurrences, 7.7\%). The incidence of to/fordatives remains low through the study period, that is, from the age group of onset at 2;00-2;06 (5 occurrences, $3.0 \%$ ) to 6;00-6;00 (4 occurrences, $2.4 \%$ ).

In view of these developmental results, the lower incidence of to/for-datives when compared to DOCs in English-Spanish bilinguals' and in English 


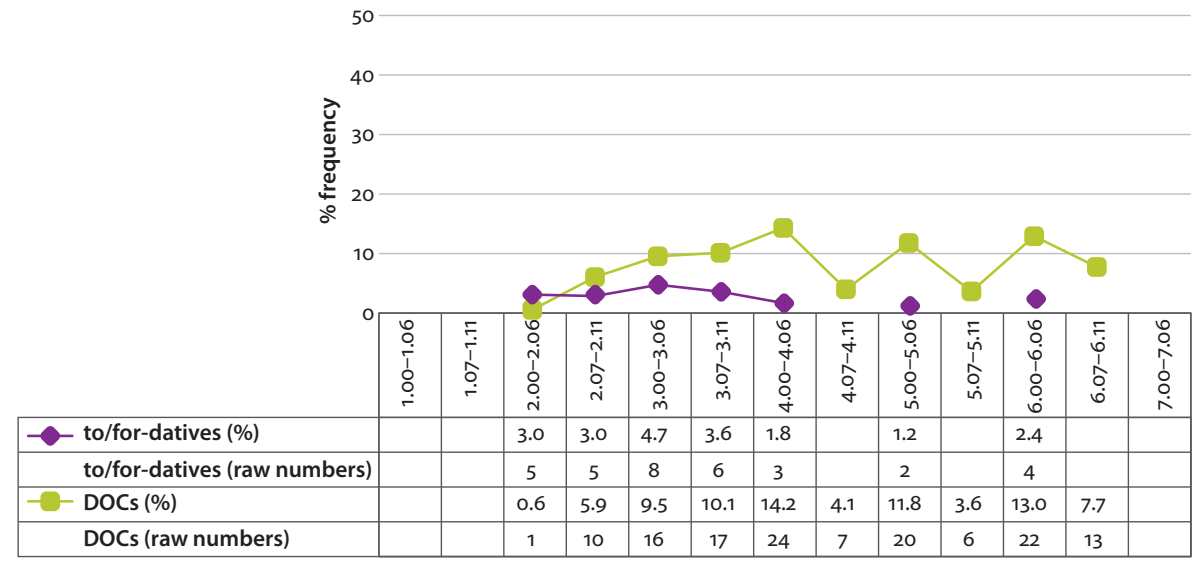

Figure 2. English-Spanish bilinguals' production of English dative alternation per age groups [100\% = overall DA structures produced by English-Spanish bilinguals]

monolinguals' data does not appear to show grounds for the syntactic non-derivational relationship between the two DA structures since a fairly similar use of DOCs and to/for-datives would have been expected through language development. Instead, the fact that to/for-datives show a low incidence could be explained by (1) the additional syntactic and semantic requirements in the production of these constructions, as also reflected in their later emergence, when compared to DOCs; and by (2) adult input factors, as will be discussed below.

The relative frequency with which English DA structures are used in the adult input has played a role in the English monolinguals' and in the English-Spanish monolinguals' output. As displayed in Figure 3, DOCs reflect higher frequency rates when compared to to/for-datives in the adult input (1,853 DOCs $>655$ to/fordatives, $73.9 \%>26.1 \%$ ) and in the English monolinguals' output (752 DOCs $>262$ to/for-datives, $74.2 \%>25.8 \%)$. Analogous findings appear in the amount of input English bilinguals are exposed to in the case of DOCs (1,528 occurrences, $71.6 \%)$ over to/for-datives (605 occurrences, 28.4\%) and this pattern is also seen in the children's output (136 DOCs $>33$ to/for-datives, $80.5 \%>19.5 \%$ ), as illustrated in Figure 4.

The higher rate in the use of DOCs when compared to to/for-datives, as observed in the adult input and in the child output, has also been reported in earlier monolingual empirical works (Campbell \& Tomasello, 2001; Sánchez Calderón \& Fernández Fuertes, 2016, 2018). This means that the findings obtained in the present work confirm that the amount of exposure to English DA in the adult input correlates with their use in the children's output, regardless of the language group (i.e., bilinguals and monolinguals) (e.g., Legate \& Yang, 2002; Yang, 2016). 


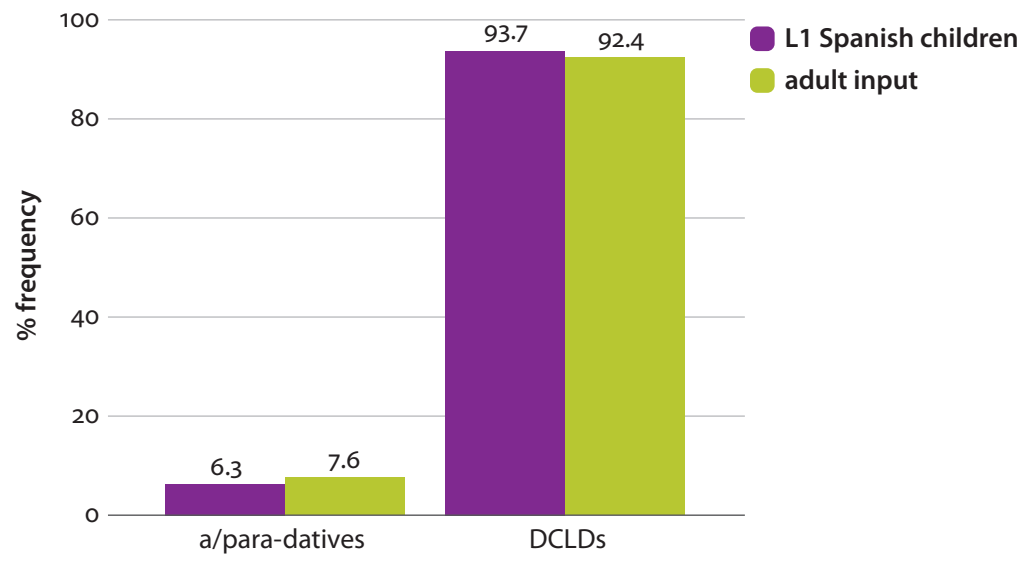

Figure 3. The production of English dative alternation in adult input and in English monolinguals' output $[100 \%=$ overall English DA structures produced by adults or by English monolinguals]

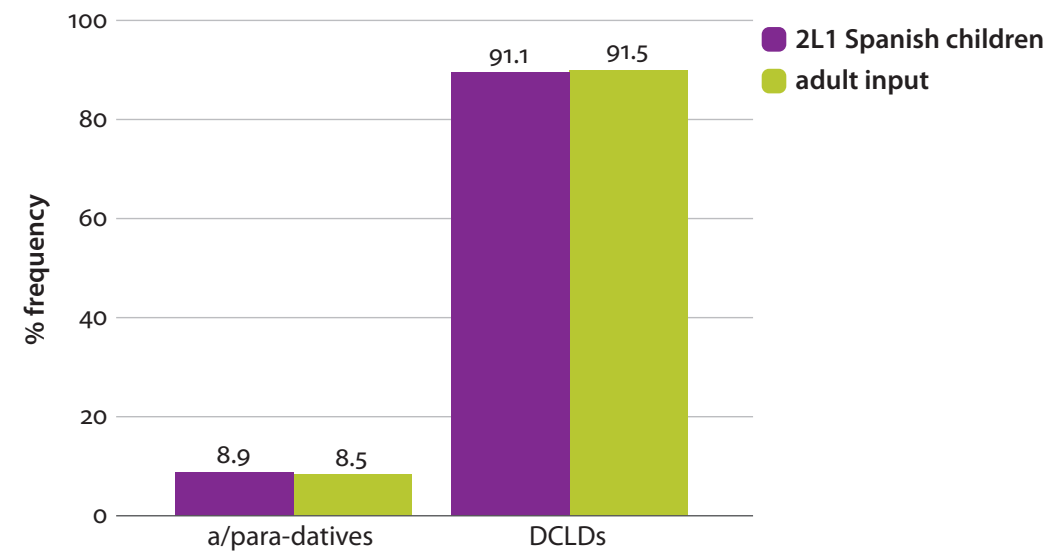

Figure 4. The production of English dative alternation in adult input and in EnglishSpanish bilinguals' output $[100 \%=$ overall English DA structures produced by adults or by English-Spanish bilinguals]

\subsection{Discussion}

In response to RQ 1, the non-significant differences between the emergence of DOCs and to/for-datives in the English monolinguals' data provides empirical evidence to suggest that the two DA structures are not derived one from the other. These findings are in line with Snyder and Stromswold's (1997) work, thus, pointing to the two English DA constructions to share a complex predicate structure (e.g., Larson, 1988) or an SC structure (e.g., Aoun \& Li, 1989). 
A syntactic derivation between the two English DA constructions would trigger a delay in the acquisition process of the derived DA (e.g., Borer \& Wexler, 1987). Since this is not the case in the English monolinguals' data analyzed, the two approaches discussed in previous sections are not supported; i.e. neither the derivation of DOCs from to/for-datives based on a prominence scale (e.g., Oherle, 1976), or a passive-like mechanism (e.g., Haspelmath, 2006; Perlmutter, 1990); nor to the derivation of to/for-datives from DOCs by means of a lexical rule (e.g., Czepluch, 1982) or a DP-movement (e.g., Aoun \& Li, 1989; Dryer, 1986).

Although the English monolinguals begin to produce English DA constructions at an approximately similar age, as per statistical analyses, to/for-datives start being produced later, and they show a lower incidence through language development, when compared to DOCs. These findings could be related to the additional property (or Property B) required in the production of to/for-datives (Snyder \& Stromswold, 1997) and, in particular, the mediated case and theta role properties of the prepositions 'to/for' (Larson, 1988; Marantz, 1984; Snyder \& Stromswold, 1997). What is more, these data could be influenced by adult input factors, as will be discussed in RQ 3 .

In the light of RQ 2, English-Spanish bilinguals show similar emergence and incidence patterns to those ones reflected in their English monolingual peers. These data suggest that English-Spanish bilingual children have acquired the syntactic non-derivational relationship between DOCs and to/for-datives. This entails that the English-Spanish bilinguals' monolingual-like patterns in the acquisition of English DA are in line with the ADH (e.g., Clark, 2009). Therefore, the syntactic properties that relate the two DA constructions in the English-Spanish bilinguals' other language (that is, Spanish) do not seem to have been transferred into the acquisition of English DA, as would have been predicted by the IDH (e.g., Meisel, 2004). Further research is required in this respect so as to elucidate the syntactic status that relates DCLDs and a/para-datives in Spanish, and their acquisition by English-Spanish bilingual children.

With regard to RQ 3, the relative frequency rates with which English DA constructions are used by adults appear to have had a positive effect on the English monolinguals' output, in line with previous works (e.g., Campbell \& Tomasello, 2001; Legate \& Yang, 2002). This is reflected in the higher relative frequency rates in the production of DOCs when compared to to/for-datives in the two groups (i.e., adults and monolingual children).

Similar results are seen in the English-Spanish bilinguals' data. In response to RQ 4, the adults' preference in the use of DOCs over to/for-datives is mirrored by the patterns found in the English-Spanish bilinguals' output. These findings reveal that the dual exposure to English and Spanish from birth by means of the one parent-one language approach (Ronjat, 1913) may have helped the analogous 
input-output patterns of DOCs and to/for-datives, akin to their English monolingual counterparts.

\section{Conclusion}

In this study, we have investigated the syntactic relationship between two types of English DA structures (DOCs and to/for-datives) in the longitudinal spontaneous production of English-Spanish bilingual and English monolingual children. Moreover, we have examined the role that adult input plays in child output in the two target language groups, and whether the simultaneous exposure to two languages, in the case of English-Spanish bilinguals, interferes in the production patterns of English DA.

There is a dichotomy in earlier formal accounts regarding the syntactic (non-)derivational relationship between DOCs and to/for-datives. In view of the English monolinguals' and the English-Spanish bilinguals' non-significant differences in the emergence of the two English DA constructions, our results suggest that DOCs and to/for-datives present a syntactic non-derivational status, which is accounted for via a shared underlying complex predicate or SC structure (e.g., Snyder \& Stromswold, 1997; Snyder, 1995, 2001).

Even though English DA structures emerge at around the age of 2;00 in the two target language groups, the later onset of to/for-datives when compared to DOCs could be explained by the additional properties of the prepositions 'to/for' (e.g., Larson, 1988; Marantz, 1993) and/or adult input effects (e.g. Campbell \& Tomasello, 2001; Snyder \& Stromswold, 1997). In the case of bilinguals, the simultaneous exposure to English and Spanish does not appear to have resulted in the transfer of the additional properties required in the production of to/for-datives as well as in the preference of DOCs over to/for-datives, as also seen in the English monolinguals' data. In order to tease these two explanations apart and given that child output and adult input are consistent with the data analyzed here, further work could look into the acquisition of prepositions in DA structures compared to non-DA structures.

Further research would address the syntactic status of Spanish DA in order to examine whether, in the case of English-Spanish bilinguals, their acquisition shows transfer of the syntactic properties underlying the English DA structures analyzed in this paper, when compared to Spanish monolinguals.

Therefore, the present study has thrown light on the debate regarding the status of English DA by comparing the English-Spanish bilingual children's ages of onset of these constructions to those in English monolingual child data. However, these conclusions should be taken with caution, since the concurrence of two facts 
does not necessarily imply they are related. That is, it could also be the case that other factors are playing a role in their similar emergence. Likewise, the preference in the children's use of DOCs over to/for-datives could also have been related to discourse factors such as animacy (Snyder, 2003) or length (Arnold, Wasow, Losongco, \& Ginstrom, 2000). Further investigation of the data could target these issues.

\section{Funding}

This research has been funded by the Castile and León Regional Government (Spain), ORDEN EDU/1083/2013, 27 December, co-funded by the European Social Funding and the University of Valladolid (Spain); as well as by the Castile and León Regional Government and FEDER (ref. VA009P17) and by the Spanish Ministry of Science, Innovation and Universities and FEDER (ref. PGC2018-097693-B-I00).

\section{References}

Aoun, J., \& Li, A. Y. (1989). Scope and constituency. Linguistic Inquiry, 20(2), 141-172.

Arnold, J. E., Wasow, T., Losongco, A., \& Ginstrom, R. (2000). Heaviness versus newness: The effects of structural complexity and discourse status on constituent ordering. Language, 76, 28-55. https://doi.org/10.1353/lan.2000.0045

Bel, A., \& Rosado, E. (2009). Person and number asymmetries in child Catalan and Spanish. In J. Grinstead (Ed.), Hispanic Child Languages (pp. 195-214). Amsterdam: John Benjamins Publishing. https://doi.org/10.1075/lald.50.09bel

Borer, H., \& Wexler, K. (1987). The maturation of syntax. In T. Roeper \& K. Wexler (Eds.), Parameter Setting (pp. 123-172). Dordrecht: Reidel. https://doi.org/10.1007/978-94-009-3727-7_6

Bruhn de Garavito, J. L. S. (2000). The syntax of Spanish multifunctional clitics and near-native competence (Doctoral dissertation). McGill University, Québec, Canada.

Campbell, A. L., \& Tomasello, M. (2001). The acquisition of English dative constructions. Applied Psycholinguistics, 22(2), 253-267. https://doi.org/10.1017/S0142716401002065

Chomsky, N. (1981). On the representation of form and function. The Linguistic Review, 1, 3-40. https://doi.org/10.1515/tlir.1981.1.1.3

Clark, E. V. (2009). First language acquisition. Cambridge: Cambridge University Press. https://doi.org/10.1017/CBO9780511806698

Cuervo, C. (2003a). Datives at large (Doctoral dissertation). The Massachusetts Institute of Technology, Massachusetts, USA.

Cuervo, C. (2003b). Structural asymmetries but same word order: The dative alternation in Spanish. In A. M. Di Sciullo (Ed.), Asymmetry in Grammar. Volume I: Syntax and Semantics (pp. 117-144). Amsterdam: John Benjamins Publishing.

https://doi.org/10.1075/la.57.07cue 
Czepluch, H. (1982). Case theory and the dative construction. The Linguistic Review, 2(1), 1-38. https://doi.org/10.1515/tlir.1982.2.1.1

De Houwer, A. (1990). The acquisition of two languages from birth: A case study. Cambridge: Cambridge University Press. https://doi.org/10.1017/CBO9780511519789

De Houwer, A. (2005). Early bilingual acquisition: Focus on morphosyntax and the separate development hypothesis. In J. Kroll \& A. De Groot (Eds.), The Handbook of Bilingualism (pp. 30-48). Oxford: Oxford University Press

Demonte, V. (1994). Datives in Spanish. Working Papers in Linguistics, 4(1), 71-96.

Demonte, V. (1995). Dative alternation in Spanish. Probus, 7(1), 5-30. https://doi.org/10.1515/prbs.1995.7.1.5

Dryer, M. S. (1986). Primary objects, secondary objects and antidative. Language, 62(4), 808-845. https://doi.org/10.2307/415173

Genesee, F., Nicoladis, E., \& Paradis, J. (1995). Language differentiation in early bilingual development. Journal of Child Language, 22(3), 611-631. https://doi.org/10.1017/S0305000900009971

Gropen, J., Pinker, S., Hollander, M., Goldberg, R., \& Wilson, R. (1989). The learnability and acquisition of the dative alternation in English. Language, 65, 203-257. https://doi.org/10.2307/415332

$\mathrm{Gu}, \mathrm{C}$. C. (2010). Cross-linguistic influence in two directions: The acquisition of dative constructions in Cantonese-English bilingual children. International Journal of Bilingualism, 17(1), 87-103.

Haspelmath, M. (2006). Ditransitive constructions in RRG and some other approaches. International Conference on Role and Reference Grammar, Leipzig, Germany.

Hulk, A., \& Müller, N. (2001). Bilingual first language acquisition at the interface between syntax and pragmatics. Bilingualism: Language and Cognition, 3(3), 227-244. https://doi.org/10.1017/S1366728900000353

Larson, R. K. (1988). On the double object construction. Linguistic Inquiry, 19, 335-391.

Legate, J. A., \& Yang, C. (2002). Empirical re-assessment of stimulus poverty arguments. The Linguistic Review, 19, 151-162.

MacWhinney, B. (2000). The CHILDES project: Tools for analyzing talk (third edition). Mahwah: Lawrence Erlbaum Associates.

Marantz, A. (1984). On the nature of grammatical relations. Cambridge: Massachusetts Institute of Technology Press.

Marantz, A. (1993). Implications of asymmetries in double object constructions. In S. A. Mchombo (Ed.), Theoretical Aspects of Bantu Grammar (pp. 113-150). Stanford: Leland Stanford Junior University Press

Meisel, J. M. (2004). The bilingual child. In T. K. Bathia \& W. C. Ritchie (Eds.), The handbook of Bilingualism (pp. 91-113). Oxford: Blackwell

Mulder, R. (1992). The aspectual nature of syntactic complementation. Leiden: Holland Institute of Generative Linguistics.

Oehrle, R. T. (1976). The grammatical status of the dative alternation (Doctoral Dissertation), Massachusetts Institute of Technology, USA.

Paradis, J., Crago, E., \& Genesee, F. (2006). Domain-specific versus domain-general theories of the deficit in SLI: Object pronoun acquisition by French-English bilingual children. Language Acquisition, 13(1), 33-62. https://doi.org/10.1207/s15327817la1301_3 
Paradis, J., \& Genesee, F. (1996). Syntactic acquisition in bilingual children: Autonomous or interdependent? Studies in Second Language Acquisition, 18, 1-25. https://doi.org/10.1017/S0272263100014662

Peccei, J. S. (1999). Child language. London: Routledge.

Perlmutter, D. M. (1990). Relational grammar. In E. A. Moravcsik \& J. R. Wirth (Eds.), Syntax and Semantics: Current Approaches to Syntax 13 (pp. 195-229). Orlando Academic Press.

Pylkkänen, L. (2002). Introducing arguments (Doctoral dissertation). The Massachusetts Institute of Technology, Massachusetts, USA.

Rowland, C. (2014). Understanding child language acquisition. London: Routledge.

Ronjat, J. (1913). Le développement du langage observé chez an enfant bilingue. Paris: Librairie Ancienne H. Champion.

Rothman, J., González Alonso, J., \& Puig Mayenco, E. (2019). Third language acquisition and linguistic transfer. Cambridge: Cambridge University Press. https://doi.org/10.1017/9781316014660

Sánchez Calderón, S., \& Fernández Fuertes, R. (2016). Dativizable or non-dativizable: That is the question? A syntactic-semantic analysis of English (non)-dativizable constructions in the production of a set of 2L1 English/Spanish simultaneous bilingual twins. Xjenza OnlineJournal of the Malta Chamber of Scientists, 4, 44-57.

Sánchez Calderón, S., \& Fernández Fuertes, R. (2018). Which came first: The chicken or the egg? Ditransitive and passive constructions in the English production of simultaneous bilingual English children. ATLANTIS. A Journal of the Spanish Association for Anglo-American Studies, 40(1), 39-58.

Snyder, W. (1995). A neo-davidsonian approach to resultatives, particles, and datives. In J. Beckman (Ed.), Proceedings of 25 North East Linguistic Society 25 (pp. 457-472). Amherst: Graduate Linguistic Student Association of the University of Massachusetts.

Snyder, W. (2001). On the nature of syntactic variation: Evidence from complex predicates and complex word-formation. Language, 77, 324-342. https://doi.org/10.1353/lan.2001.0108

Snyder, K. (2003). The relationship between form and function in ditransitive constructions (Doctoral dissertation), University of Pennsylvania, Philadelphia, USA.

Snyder, W., \& Stromswold, K. (1997). The structure and acquisition of English dative constructions. Linguistic Inquiry, 28(2), 281-317.

Torrens, V., \& Wexler, K. (2000). The acquisition of clitic doubling in Spanish. In S. M. Powers \& C. Hamann (Eds.), The Acquisition of Scrambling and Cliticization. Studies in Theoretical Psycholinguistics 26 (pp. 279-297). Dordrecht: Springer. https://doi.org/10.1007/978-94-017-3232-1_11

Yang, C. (2016). The price of linguistic productivity: How children learn to break the rules of language. Cambridge: Massachusetts Institute of Technology Press. https://doi.org/10.7551/mitpress/9780262035323.001.0001 
Address for correspondence

Raquel Fernández Fuertes

Universidad de Valladolid

English Department

Facultad de filosofía y letras

Plaza Campus Universitario s/n

Valladolid 47011

Spain

raquelff@uva.es

(D) https://orcid.org/0000-0002-3889-6194

\section{Publication history}

Date received: 16 October 2018

Date accepted: 10 March 2020

Published online: 15 May 2020 